Chapter 4

\title{
The Management of Dementia in Primary Care
}

\author{
Luc Pieter De Vreese, Luigi De Salvatore, Lara Rovesta and Andrea Fabbo \\ Additional information is available at the end of the chapter \\ http://dx.doi.org/10.5772/62762
}

\begin{abstract}
High-quality in-home primary healthcare services are pivotal for people with dementia and their families to avoid inappropriate hospital admissions and premature nursing home placement, which are associated with worsened quality of life of both the person with dementia and his family and financial burden.

This chapter gives a qualitative overview of the evidence on the efficacy and effectiveness of different primary care models covering all the stages of the disease from the onset of the disease until the more advanced stages with a particular focus on the management of behaviour and psychological disorders.

A detailed description is provided of the primary care model of the Province of Modena for people with dementia and their families in which the general practitioner plays a central role both in the diagnostic process and in follow-up and closely collaborates with first- and second-level healthcare professionals. This "collaborative care" network is able to address timely the continuously changing needs of these frail people and their caregivers, including acute severe behavioural and psychological disorders. A 10-item composite indicator of appropriateness of care by the general practitioner has been recently introduced to further improve the quality of care within primary care.
\end{abstract}

Keywords: Behavioural and psychological disorders, case-finding, models of primary care, dementia, family caregiver, cognitive screening tests

\section{Introduction}

Globally, the number of persons living with dementia (PWD) is projected to increase exponentially as population ages, becoming one of the most serious human, social, and economic 
burdens of this century. According to the World Alzheimer Report 2015 [1] it is estimated that 46.8 million people around the world live with dementia now and that this number will almost double every 20 years. At present, the estimated global incidence of dementia is 9.9 million new cases, implying one new case every 3.2 seconds. The most recent population based prevalence study in Italy [2] shows that one quarter of 80+ year old people have dementia, most of them in the advanced stages of the disease with prevalence rates that continue to rise gradually even in extreme ages: $15.7 \%$ in people aged $80-84$ years to $52.8 \%$ and $65.9 \%$ in people aged 95-99 and in centenarians, respectively [2]. Also the incidence rates of dementia per 100 person-years do not level off but increase gradually ranging from 6 person-years at 80-84 years to 20-21 person-years at 95-99 years (Lucca $U$ et al., unpublished data).

Dementia is defined as a progressive major neurocognitive syndromal (group of signs/ symptoms) disorder characterised by neuropsychological impairments, reduced ability to perform activities in everyday life and behavioural and psychological symptoms of dementia (BPSD). These deficits cause significant impairment in social or occupational functioning and represent a significant decline from a previous level of functioning [3].

The progression of the disease greatly differs from one type to another, but most types of dementia are characterised by an early loss of declarative memory and progressive deficits in other cognitive domains (e.g., executive function, language, abstract reasoning) significantly interfering with overall daily-live functioning. In addition, over $90 \%$ of PWD manifest at least one challenging behaviour or clinically relevant psychological symptom during the course of their disease [4].

The increasing number of PWD will lead to a rising demand for informal and formal care services in order to attend to the needs of this group of people. The possibility of getting support depends on numerous interrelated factors such as patients' and carers' (socioeconomic) characteristics, care setting, provision of services, availability of healthcare providers and the degree of integration among care networks. Some research suggests that cohabitant family caregivers (CGs) could be replacing formal support services provided that they accept supervision or advice from social and primary healthcare services. Unfortunately, many CGs do not connect their relative with social and healthcare professionals, which may constitute a disadvantage for both of them [5]. There are different reasons why CGs do not search formal support among which the principal are stigma surrounding dementia, CGs' perceived lack of need and support, PWD's refusal to accept help, service characteristics and lack of knowledge about service availability [6,7]. All these findings show PWD as a vulnerable group. Developing interventions, such as case/care management which allow the coordination between different agents involved in community care might offer the possibility necessary to satisfy the needs of PWD and their CGs in the primary care context [8].

Obstacles to detecting dementia at the primary care level include limited time resources [913], insufficient expertise, flaw in skill set, fear of making an erroneous diagnosis, unsatisfactory reimbursement, and deficiencies in the coordination between family physicians (henceforth called general practitioners (GPs)) and community services [14-18]. 
Not surprisingly, two-thirds of all dementia and $91 \%$ of incipient dementia remain undetected in the primary care setting around the world. Even when GPs accurately recognise dementia, the quality of management of the disease after the diagnosis frequently appears suboptimal. Initiation of dementia-specific drug treatment [19], assessment and management of BPSD, safety issues, side effects of psychotropic drugs and of CGs' stress and burden [20], coordination of primary healthcare partners [21], implementation of support for PWD and their CGs [22] represent the main challenges for providing quality dementia care by the GPs. Inadequacies in the diagnosis and management of dementia have been found to increase the risk for hospitalisation and nursing home placement contributing substantially to the economic burden of dementia [23].

Different models of care have been designed to help GPs in detecting dementia and in delivering better dementia care. Research in this field has yielded to date mixed results in terms of efficiency and effectiveness [24-28]. In contrast, a collaborative care model in which an interdisciplinary team works with both the PWD and the CG, and which is integrated with a primary care network, improves adherence to dementia care guidelines and reduces BPSD of the PWD and stress and depression of their CGs [29, 30]. Although limited in scope, research suggests that including geriatric specialists in the detection of dementia increases the rates of screening people for dementia [18]. In a recent exploratory study [31], dementia care was delivered through a system involving three groups of healthcare providers: (a) GPs involved in the primary care network for identification and management of dementia; (b) a geriatric assessment team (a GP who had extensive training in geriatrics and nurses specialised in assessing frail elderly) and (c) community care composed of nurses and other healthcare professionals (e.g., social workers, occupational therapists, psychologists). The geriatric assessment team assisted with the evaluation of the PWD and with client-tailored care planning (exhaustive listing of problems, recommendations, multidomain interventions and follow-up). Community care delivered personal support services to the PWD and their families integrated with the primary care network. Although it was assumed that this current approach to caring for PWD would have resulted in high-quality dementia care, a retrospective analysis of the charts of these three groups of healthcare providers evidenced several gaps and inconsistencies, underscoring the need of further research to assess whether the overall quality of dementia diagnosis and management at the primary care level may be achieved through a collaborative model that integrates different healthcare services [31-33].

\section{Early diagnosis and case finding in primary care; the diagnostic burden.}

Despite the worldwide increased recognition of the early symptoms of dementia, this disease still remains too often a hidden problem, especially in resource-limited communities. Many family members do not seek help, and GPs seldom come across cases (see below) because loss of memory and other related cognitive functions are thought to be part of an usual cognitive aging process (i.e., ageism) and not a medical (i.e., pathological) condition. Dementia, however, is a significant source of burden both for the PWD and his/her family. Hence, more research on interventions to promote help-seeking behaviour and to improve the diagnostic expertise 
of non-specialist healthcare providers, is urgently needed. For instance, it is mandatory to compare the accuracy of the clinical evaluations done by these first- and second-level healthcare providers against a standard assessment process for the diagnosis of dementia by a specialist. If it could be shown that a network of non-specialist healthcare providers is able to reliably identify dementia cases in the community and in the primary care setting, then it might deliver simple and effective interventions in these settings with supervision and counselling as needed by the specialists [34].

GPs are usually the first health professionals that either patients or their families contact if concerned about memory decline. However only $60 \%$ of the people who meet the diagnostic criteria receive a formal diagnosis of dementia: failure rates have been estimated between $50 \%$ and $80 \%$ for moderate-to-severe dementia and up to $91 \%$ for mild cases. Yet, owing to their long relationship with patients (and their families), GPs are in a favourable and unique position to collect the information needed to define the patient's cognitive, functional and behavioural profile. This is pivotal not only for the diagnostic process but also for care planning tailored to the needs of the PWD and his/her family and for the assessment of treatment effects. GPs underdiagnose dementia for several reasons; apart from those already mentioned above, there is also the limited availability of guidelines specific for the GP's practice that might allow to better approach the diagnostic burden of dementia, especially in its early stages [34, 35].

Although general practice is usually the first point of contact for patients with memory problems or other symptoms of dementia, GPs appear reluctant to use brief cognitive tests and to refer patients for early assessment, particularly in disadvantaged older people with functional impairment [36]. On the other hand, there is increasing evidence that people want earlier diagnosis, with younger healthcare professionals perceiving its usefulness and the international guidelines emphasising the importance of early diagnosis [37-40]. In primary care there is a need to develop training in assessment so that clinicians are more aware of dementia to deliver a timely diagnosis [41]. Studies based on a focus-group methodology about practitioners' knowledge have shown that primary care recognition can be enhanced; however, this does not always result in greater adherence to practice guidelines [42]. Education should also include assessment of GPs' needs, otherwise facilitation of system change does not improve performance or health outcomes and it is suggested that small group education is important. A 'whole system' approach has been advocated to improve self-management of long-term conditions, but interventions have limited impact on patients' outcomes [43, 44].

Across the European Union more than 50\% of PWD never receive a specialist diagnosis or do so only at the late stage of disease or at a time of crisis, despite an growing evidence that early diagnosis and subsequent interdisciplinary intervention are cost-effective [45, 46]. Early diagnosis in dementia within primary care is important as this allows PWD, their CGs and care networks to set up support services and to act proactively for the future, in accordance with the adage of "spend to save". The North of England Evidence Based Dementia Guideline Development Group states that 'population screening for dementia in the over 65 s is not recommended; a case finding approach is recommended'. It makes the recommendation that GPs should consider using formal cognitive testing to enhance their clinical judgment [47]. However, the development group fails to recommend which tests to use and how often to use them throughout the elderly population at risk. Although this group, despite its name, makes recommen- 
dations based on the clinical opinions of GPs, recommendations based on evidence are given more weight by some US organizations [48].

A number of simple tools are available for use in the community to make an initial assessment of a patient's cognitive function [49]. The most commonly used cognitive assessment tool is the Mini-Mental State Examination (MMSE); marked out of 30, a score of less than 25 is suggestive of dementia [50]. However, this examination can take up to 15-20 minutes to complete and may not be practical for use within a primary care consultation, which is usually allocated just 10 minutes. The General Practitioner Assessment of Cognition (GPCOG) [51] and two other cognitive screening tests, the Mini-Cog Assessment Instrument [52] and the Memory Impairment Screen (MIS) [53], have been found to be as clinically and psychometrically robust and more appropriate for use in primary care than the MMSE. The GPCOG is estimated to take 5 to 7 minutes to complete, with questions for both the patient and carer to answer, making it more relevant for GPs. An alternative, developed in primary care, is the Six-Item Cognitive Impairment Test (6-CIT), which performs as well as the MMSE, but is easier to use [54]. The administration of a clock-drawing test (CDT) may also be a useful quick and simple test for the GP's routine practice [55]. A short video produced by the American College of Physicians Foundation and the Alzheimer's Association demonstrates how to use the Mini-Cog for the assessment of cognitive impairment during a primary care visit [56]. In addition, an 8-item informant tool called the $A D 8$ is a very useful method of gathering information from someone who knows the patient well [57]. A recent systematic review suggests that if length is not a major consideration, the MMSE [50] may remain the best tool for primary care clinicians who want to make a syndromal diagnosis of dementia [58].

Yet, another recent evidence-based recommendation on Practical Diagnosis and Management of Dementia due to Alzheimer's disease in the primary care setting does not advocate the MMSE as a screening test because of its length, education and literacy biases, and financial burden due to copyright issues [59]. As no single cognitive screening tool can actually be considered the gold standard, a reasonable proposal may be to familiarise with one of the above listed suitable instruments and incorporate it into routine practice [60].

Technology platforms such as diagnostic support aids, offer an important solution but need further research as there are accuracy and reliability issues with subsequent reduced helpseeking behaviours due to false-negative results, or generating unnecessary distress with falsepositive results [61]. A recent proposal from the Italian Society of General Practitioners (SIMG) to improve early diagnosis of dementia in general practice, reviewed the literature and ascertained the contributing factors for GPs' missed or delayed diagnosis of dementia (Table 1), the Brief Psychometric Screening Tools with an administration time $<5$ minutes and with negative predictive values superior to those of the MMSE (Table 2) and the guidelines targeted for GPs' detection of dementia [62-69].

The identification of possible cases of dementia in the primary healthcare setting and in the community needs medical practice-based educational programmes and awareness-raising campaigns. Short informant questionnaires and cognitive tests should be used to confirm these cases. A formal diagnosis of a probable primary progressive dementia at first- or secondhealthcare level can be made only after an exhaustive past and present medical review, 
included drug therapy and alcohol abuse in order to rule out other common (reversible) causes of cognitive impairment and decline [60-69].

\begin{tabular}{|c|c|}
\hline Cultural barriers & $\begin{array}{l}\text { 1. Absent/limited education during undergraduate or postgraduate training in } \\
\text { Medicine } \\
\text { 2. Ageism: GPs who attribute cognitive complaints to age; patients or families lacking } \\
\text { insight and not referring for assessment }\end{array}$ \\
\hline Clinical variability & $\begin{array}{l}\text { Dementia subtypes develop slowly, in years. Many of their early clinical pictures may } \\
\text { be insidious due to slight differences with normal ageing. Failure to recognise BPSD, if } \\
\text { these are the first signs before obvious memory complaints/disorders or functional } \\
\text { impairment. }\end{array}$ \\
\hline Practical issues & Lack of time, financial resources and GP-focussed guidelines \\
\hline
\end{tabular}

Reproduced with permission from Pirani et al., 2011 [69].

Table 1. The diagnostic burden of dementia for GPs

\begin{tabular}{|c|c|c|c|c|c|c|c|}
\hline \multirow[b]{2}{*}{ Test } & \multicolumn{3}{|c|}{ Memory } & \multirow{2}{*}{$\begin{array}{c}\text { Praxis, } \\
\text { visuospatial }\end{array}$} & \multirow{2}{*}{$\begin{array}{l}\text { Aphasia, } \\
\text { verbal } \\
\text { fluency }\end{array}$} & \multirow[b]{2}{*}{$\begin{array}{l}\text { Functional status } \\
\text { from informant }\end{array}$} & \multirow[b]{2}{*}{$\begin{array}{c}\text { Cross-cultural } \\
\text { validation }\end{array}$} \\
\hline & Orientation & $\begin{array}{c}\text { STM } \\
\& \text { LTM }\end{array}$ & $\begin{array}{c}\text { General } \\
\text { information }\end{array}$ & & & & \\
\hline$\overline{\mathrm{AMT}}$ & $x$ & $x$ & $x$ & & & & \\
\hline$\overline{\mathrm{CDT}}$ & & & & $x$ & & & $x$ \\
\hline CP-COG & $x$ & $x$ & & $x$ & $X$ & $x$ & $X$ \\
\hline SPSMQ & $x$ & & $x$ & & & & $x$ \\
\hline 6-CIT & $X$ & $X$ & & & & & \\
\hline Mini-COG & & $X$ & & $X$ & & & \\
\hline MIT & & $X$ & & & & & \\
\hline$\overline{\text { BAS }}$ & $X$ & $X$ & & & $X$ & & \\
\hline
\end{tabular}

Adapted with permission from Pirani et al., 2011 [69].

AMT, Abbreviated Mental Test; CDT, Clock Drawing Test; CP-COG, General Practitioner Assessment of Cognition; SPMSQ, Short Portable Mental State Questionnaire; 6-CIT, 6-Item Cognitive Impairment Test; Mini-COG, Mini Cognitive Assessment Instrument; MIS, Memory Impairment Screen and BAS, Brief Alzheimer Screen.

Table 2. Selection of brief psychometric screening tests.

\section{The collaborative model for dementia in primary care}

As outlined above, collaborative care for the treatment of dementia resulted in a significant improvement in the quality of care and in BPSD among primary care patients and their CGs. These improvements were achieved without significantly increasing the use of antipsychotics or sedative-hypnotics [29]. Indeed, BPSD represent a major challenge in the care of PWD. These 
symptoms, which include a broad range of distressing behaviours and psychological reactions, affect the health and quality of life of both the PWD and his/her CG. BPSD are not simply a manifestation of advanced dementia. For instance, behavioural abnormalities are reported in $35-75 \%$ of people with mild cognitive impairment with the most common being depression, apathy, anxiety and irritability [70]. Leaving patients' BPSD untreated, undertreated or treated improperly has been associated with patients' excess disability, poor management of comorbid conditions, increased hospitalisation rates, premature institutionalisation, suffering for both the PWD and the CG and substantial increase in financial costs.

Some studies compared the effectiveness of collaborative care management with usual care for older PWD with comorbidity or multimorbidity that is typically found in primary care. The extreme heterogeneity of the targeted population and the fact that this model starts from the perspective of the GP probably explain a major treatment effect on BPSD rather than on the other domains of dementia like cognition and everyday functioning [71, 72].

In the context of collaborative dementia care models (or others models of in-home care services such as integrated care, consumer directed care and restorative care) [73] psychosocial interventions play a leading role. Psychosocial interventions in dementia are nonpharmacological approaches involving interactions between people to support cognition, emotion, meaningful activity and interpersonal relationships. They aim to enhance or maintain quality of life by maximising psychological and social function in the context of existing disabilities [74]. Effective psychosocial interventions are usually multicomponent, individualised and targeted to the context and personal needs of both the PWD and his/her family [74, 75]. A range of individually tailored approaches have been developed including cognitive stimulation, cognitive rehabilitation, reminiscence therapy, emotion-based care [76] and adaptations from standard psychological therapies such as cognitive behaviour therapy which can be used with the person and/or the carer to reframe experiences of dementia and thus improve quality of life and coping with the condition [77, 78]. Other approaches include involving pets, music, dance, exercise and art therapies, although the evidence for these has yet to be established. Group-based support in community dementia care albeit an intuitively popular approach is so far only weakly evidence-based. An exception is cognitive stimulation therapy, an activity and discussion group therapy that aims to improve quality of life by enhancing cognitive and social functioning [79-81] and it has been recommended 'for all people with mild to moderate dementia' by the NICE Guidelines for Dementia, although not all PWD want to engage in group therapy. Psychosocial interventions that help PWD and families to cope with changing roles and relationships and that teach ways to minimise the impact of dementia are an important focus for those in dementia care [82]. Individualised interventions such as cognitive rehabilitation [83] and occupational therapy [84] usually involving family or friends helping the PWD to achieve their goals in life, remain an important avenue for the future of psychosocial interventions in dementia primary care. Such interventions can also have components to meet the needs of the family carers [85]. The implementation of psychosocial interventions in primary care often focus on educational interventions for GPs, although studies of the quality of care in primary care suggest that more psychosocial approaches can be undertaken [86] with the application of carefully developed quality indicators for the delivery of dementia care [87]. 
The paucity of research in psychosocial approaches in primary care presumably stems from a poor understanding of the value of psychosocial interventions in community settings [88]. Information provision is seen as a key to dementia care support but this does not appear to be done timely or tailored to the constantly changing needs of PWD and their families. This may be because of the application of a medical management model where a social disability framework for delivering support in primary care is more relevant in guiding dementia care practice [89]. For these reasons the management of PWD and their CGs should be organised on the model of integrated care, described as "the management and delivery of health services so that clients receive a continuum of preventive and curative services, according to their needs over time and across different levels of the health system" [90].

In primary care, the medication management is a key element of providing optimal care for PWD [91]. The current focus has been on the use of first- and second-generation antipsychotics to treat challenging behaviours and the recent UK guidelines targeted a reduction in such usage by two-thirds [92]. However, effective medication management in dementia is much broader than just the appropriate treatment of BPSD. PWD may rely upon informal carers to manage their medication and these carers may conduct various medication management activities, including the recognition and management of side effects and the decision to administer or not medication [93]. GPs should be aware that dementia increases the likelihood that key risk factors-including inappropriate prescribing, old age, adherence issues, drug interactions, comorbidity or multimorbidity and polypharmacy—-for medication-related adverse events are present [94]. Medication errors may be more common in PWD because of the involvement of multiple health and social care professionals; the primary-secondary care interface may be particularly risky [95]. Specific factors including frailty and comorbidity or multimorbidity may increase the risk of adverse reactions. Falls are a major cause of injury in older people [96]. Psychotropic drugs including antidepressants, neuroleptics and benzodiazepines belong to one of the main groups of medications associated with falls, the so-called 'fall risk increased drugs' (FRID). Polypharmacy is also a risk factor for falls and older people should have regular medication reviews. If possible, psychotropics and other unnecessary medicines should be discontinued to reduce the risk of a fall. There is also increasing evidence that treatments specifically administered for the symptoms of dementia cause falls. Cholinesterase inhibitors (ChEI) notably cause bradycardia, arterial hypotension or hypertension, syncope and dizziness with increased fall risk and hip fracture [97]. If family carers are not aware of the potential link, they may continue to administer ChEI despite a recent history of falling in the patient. In summary, safe and effective medication management in dementia is complex and difficult to achieve. A collaborative approach that improves outcomes by linking primary and secondary healthcare services-including general practice and pharmacy-with social care needs to be developed. A key outcome of such a collaborative approach would be to support informal CGs to optimise the management of medication.

\section{The case management model in primary care}

PWD and their CGs often encounter services that are fragmented, protocol-driven and only weakly tailored to individual and family needs. Because dementia is a more or less slowly 
progressive disease, the needs of the PWD may change greatly over time, requiring consequently support from a complex and flexible matrix of social networks and services, as well as from family CGs who should adapt themselves to the cumulative repercussions inherent to the disease (and associated chronic or new onset) organic pathologies of their relative with dementia. In addition, the interaction of medical professionals, PWD, family, and systems barriers in primary and secondary care explain why providing timely, proactive, responsive, well-coordinated and patient-centred clinical care is so difficult $[9,98]$.

In Europe, there is a great need to reconfigure services for PWD and their families so that they become more patient-centred and family-centred. Case management approaches that start with an assessment of needs shared between patients, caregivers and professionals, show promise as a way to improve the quality of life of PWD and their families, reduce health expenditure (e.g., inappropriate hospital admissions), and produce societal gains [99]. A recent systematic review of randomised controlled trials (RCTs) of case management for PWD and their CGs concluded that the evidence for the efficacy of case management with reference to cost and resource usage is not strong enough and that further studies ought to consider who might benefit more from case management [98]. On the other hand, some well-conducted, long-term studies have demonstrated how case management can delay institutionalisation, with potentially important health and economic gains [100-103].

Case management was found to not affect nursing home placement, hospitalisation and emergency room (ER) referrals [104], and consistent with this, the reviews agreed that case management produced small to no decreases in resource utilisation when healthcare expenditure, hospitalisation or institutionalisation were considered [105]. There is a limited number of RCTs of in-home care/case management for PWD. These studies measured a diversity of outcomes that makes it difficult to draw conclusions. A Finnish study found that case management was effective in deferring nursing home placement, particularly for persons with severe dementia; however, by the end of the 2-years follow-up, the numbers of participants admitted to long-term residential care were similar for case management and usual care groups [106]. An American study over 12 months found that in comparison with usual care, casemanaged clients improved adherence and quality of care on dementia guidelines, increased use of community agency assistance, and patient health-related quality of life, overall quality of patient care, caregiving quality, social support and level of unmet caregiving assistance needs [101].

Another study found that characteristics of case management, which negatively influence implementation, are low intensity of case management (e.g., infrequent follow-up), a large case load (60 patients or more per case manager), and a reactive (rather than proactive) approach to care [107]. In the Netherlands, the model of case management in which case manager and client services are embedded within one type of organisation is more successful in facilitating implementation of care compared to the model where the case manager coordinates services from a range of organisations. In summary, case management for PWD may increase the use of community-based services and delay nursing home admission [74].

There is a great need to reconfigure services for PWD and their families to become more patient- centred, using case management approaches that start with an assessment of needs 
shared between PWD, CGs and healthcare professionals. The Case Management Society of the United Kingdom defines case management as "a collaborative process which assesses, plans, implements, co-ordinates, monitors and evaluates the options and services required to meet an individual's health, and social care, educational and employment needs, using communication and available resources to promote quality cost effective outcomes"[98]. Case management, as a clinical management technique, offers a way of creating patient-centred interventions and has been shown to be effective for some people with multiple or single long-term care needs. However, the diffusion of case management methods has been very variable, and there is a need to overcome the block that impedes the transfer of knowledge into practice.

\section{The "Modena Primary Care Dementia Project"}

\subsection{Historical overview}

In 1999 the Regional Government of Emilia-Romagna deliberated the "Regional Dementia Project" (D.G.R. 2581/1999), an act that provides funds for the organisation of Health and Social Welfare Services in the community for PWD aimed at (a) ensuring a correct and timely diagnosis of dementia; (b) ameliorating the health-related quality of life and overall quality of care of PWD; (c) extending the period of home care for as long as possible; (d) adapting, expanding and specialising the existing health and social network services for PWD; (e) enhancing the role of the family associations and (f) qualifying the care processes of hospitalised PWD. The regional project's actions to guarantee global care plans, follow-up and continuity of (in-home) care of PWD include (a) creation of a network of specialist centres for cognitive disorders and dementia (CCDD) with competencies in diagnosis and care planning; (b) increase of formal and informal support for families of PWD; (c) amelioration of the network services tailored to the individual needs and resources of the individual PWD and his/her CGs and (d) widespread training and education of social and healthcare professionals.

According to this regional dementia project, and given the GP's pivotal role in the timely diagnosis of dementia, the Local Authority for Health (Azienda Sanitaria Locale, ASL) of Modena and the Department of Primary Care together with the most representative GPs' organisations, implemented in 2002 a targeted protocol, called "Cognitive Disorders Project," to involve on voluntary basis GPs in dementia screening by means of accreditation courses promoting an uniform screening assessment. In 2007, the Director of the Health Thrust of the ASL of Modena approved a new agreement with the GPs consisting of a protocol for taking care of PWD and their families by the GP and the CCDDs. This renewed protocol is aimed at improving (a) integrated care of PWD through a more fruitful and assiduous dialogue between the GP and CCDDs already from the start of the diagnostic process of dementia (b) follow-up with ongoing monitoring of the treatment schedules for ChEI, Memantine and second-generation antipsychotics (olanzapine, risperidone, quetiapine, clozapine) according to note 85 of the Agenzia Italiana del Farmaco (AIFA, Italian Agency of Drugs) and of the overall healthcare of PWD (c) the effective role of the GPs as consultants, with particular reference to BPSD in crisis situations 
and (d) health and non-health in-home care of PWD in the more advanced stages of the disease avoiding unnecessary ER referrals, hospitalisation and premature nursing home placement.

The final outcome of these two protocols are to improve the quality of life and health of PWD and their families, satisfying the preference of PWD (and/or their families) to remain living at home and maintain normality for as long as possible deferring long-term residential care in agreement with the results of some RCTs of integrated care models for the frail elderly including people with cognitive impairment [108].

\subsection{Dementia case-finding (Form A)}

When the GP suspects an incipient dementia, he/she administers the Symptom of Dementia Screener (SDS) [109] and the MMSE [50]. When the SDS score is $\geq 5$ and the MMSE score is $<26$, GP quantifies the patient's somatic comorbidity by means of the Cumulative Illness Rating Scale (CIRS) [110] and his functional efficiency through the administration of the IADL [111] and ADL [112] scales. In addition, the GP prescribes blood chemistries and instrumental examination, as suggested by the international diagnostic guidelines such as the DSM-IV-TR [113]. Once collected all the above information, including anamnesis regarding family history of dementia, past or present psychiatric diseases or alcohol abuse and current drug therapy, the GP refers the patient with the completed Form A in all its parts to one of the 10 specialist CCDDs present in the Province of Modena for a differential diagnosis (usual cognitive aging, different types of mild cognitive impairment, dementia with a typological diagnosis), therapy and care planning. As needed, the family may be referred to a clinical psychologist for individual or group counselling.

\subsection{Follow up (Form B)}

After the diagnostic work-up, the patient is returned to the care of the referring GP with (typological) diagnosis and advices for follow-up with annual compilation of Form B which includes, in addition to the patient's cognitive (MMSE), functional ([I]ADL) and physical health (CIRS) status, data regarding the recourse to day centre or (temporary respite) residential care and the implementation of a " health in-home care service" integrated with local public or private social service systems (the so-called Assistenza Domiciliare Integrata, ADI). The GP also reports the presence of psychological distress of the family CGs and may plan psychological and/or social support according to the following eligibility criteria: the context or consequences of caregiving and of well-being and treatment motivation of the family carer.

The following paragraphs illustrate some results of the most relevant aspects of the Modena Project collected in 2013.

\subsection{GPs' adhesion to the project}

About 68\% (385 out of 568) of the GPs practicing in the 7 Health Districts of the Province of Modena are actively participating into this project on completely voluntary but remunerated basis. Between 2007 and 2013, 9542 PWD have been enrolled by the GPs (Form A and B) with 5195 cases (females $=64.5 \%$; median age $=86$ years) still active (Form B for follow-up) in 2013 . 


\subsection{GPs' referral for diagnosis to the specialist centres}

Of 4530 outpatients referred by the GPs for the first time to the specialist of CCDDs, 2778 patients received a diagnosis of dementia (61\%), whereas 865 patients $(20 \%)$ were considered at risk (mild cognitive/vascular impairment). Only 598 cases (14\%) did not display any sign/ symptom of cognitive impairment or dementia. Though these figures suggest an appropriate referral by GPs to the specialist of CCDD, it should be noted that in reality only $8 \%$ of PWD aged $65-80$ years and $48 \%$ of PWD with age $>80$ years are enrolled by the GPs according to the estimated prevalence of dementia in these two age subgroups (i.e., $4 \%$ and $16.8 \%$ respectively) (data from the Department of Clinical Epidemiology of Modena, unpublished), confirming the universally observed trend to underdiagnose dementia in primary care.

\subsection{Ordinary and semi-urgent home visits}

In 2013, 3706 home visits (i.e., at home, in nursing homes and in day care centres) have been conducted, some of them together with GPs, which correspond to $22 \%$ of the total (first and control) visits ( $n=16,623)$, confirming the important work done by the CCDDs at the provincial level as part of the Department of Primary Care. As presented in Table 3, eligibility criteria for ordinary and semi-urgent home visits have been established in agreement between the specialists of the CCDDs and the GPs. An analysis of the 65 "semi-urgent" home visit requests received by the CCDD of the Health District of Modena in the first half of 2014 is as follows. Only 8 of 65 requests were followed by a home visit within 7 working days from the GPs' phone call; 9 requests were resolved with a telephone conversation between the referring GP and the Geriatrician; 26 cases have been turned into "semi-urgent outpatient visits" at the CCDD and 22 in ordinary home visits. In 12 PWD (18.5\%), it was necessary to activate other services: one patient was sent to the ER, one to a territorial Centre of Mental Health, three patients were assessed by a Multidimensional Assessment Unit-a team composed of a Geriatrician, a Nurse and a Social Worker - two patients were transferred to a Special Hospital Unit (SHU) for Dementia, three to an Alzheimer Day Centre (ADC) and two to a temporary residential Special Care Unit (SCU). The latter three structures are an integral part of the integrated network of health and social services dedicated to the diagnosis and treatment of PWD with BPSD related to dementia, environment or caregiving (ADC and SCU) or secondary to organic or iatrogenic comorbidities or multimorbidities (SHU) according to the evidencedbased model of structures and organisations for the care of major BPSD (Alzheimer Cooperative Valuation in Europe, www.alcove-project.eu).

\subsection{Integrated domiciliary care}

As explained above, the Modena project pays great attention to support PWD in their own homes. In-home care for PWD is delivered in close cooperation with the treating GP across the province through a wide range of actions (see Figure 1) ranging from the aforementioned agreement act with the GPs for taking care of PWD and their families to the use of respite care (nursing homes, SCU, ADC) and to an economic support (care voucher)-similar to the consumer-directed care model - thanks to regional funds for long-term care of frail elderly for low-income families who decide to care for their loved at home. 
Health and social services intervene whenever one of the following trigger conditions is verified (a) the PWD lives alone without direct relatives and a valid homemaker assistance; (b) home environment requires adaptation to the PWD's new onset needs; (c) family or formal CGs are in trouble and unable to manage BPSD; (d) the PWD's clinical picture or social conditions undergo a substantial worsening that requires the search for an alternative care plan and (e) the PWD evolves to a terminal stage of illness.

\footnotetext{
- Bedridden patient or with major locomotion difficulties (rendering a problematic transport to the CCDD)

- Patient with preserved ambulation but frankly uncooperative and/or depressed who refuses to leave the house

\begin{tabular}{ll}
\hline Ordinary home visits & Semi-urgent home visits (within 7 working days) \\
\hline Persistent BPSD: aberrant motor activity, & Persistent (for at least 10 days), major and worsening BPSD: aberrant \\
vocalizations, physical aggression, insomnia & motor activity, continuous vocalizations, physical aggression, \\
& \begin{tabular}{l} 
delusions and/or hallucinations with functional impact, insomnia) \\
\hline
\end{tabular}
\end{tabular}

Exclusion criteria:

- Organic precipitating causes such as infection or uncontrolled pain (e.g., (S)DSD)

- BPSD refractory to drug therapy and psychosocial interventions already undertaken before

CCDD, centre for cognitive disorders and dementia; BPSD, behavioural and psychological symptoms of dementia and (S)DSD, (subsyndromal) delirium superimposed on dementia.
}

Table 3. Inclusion and exclusion criteria for ordinary and semi-urgent home visits

The latter service is delivered provided that the following conditions are met (a) inability to easily reach points of care; (b) the presence of at least a prevalent organic symptom (e.g., aspiration pneumonia); (c) presumed life expectations inferior to 4 months; (d) little opportunity to intervene with effective care and (e) family CGs are adequate and are integrated with the healthcare team.

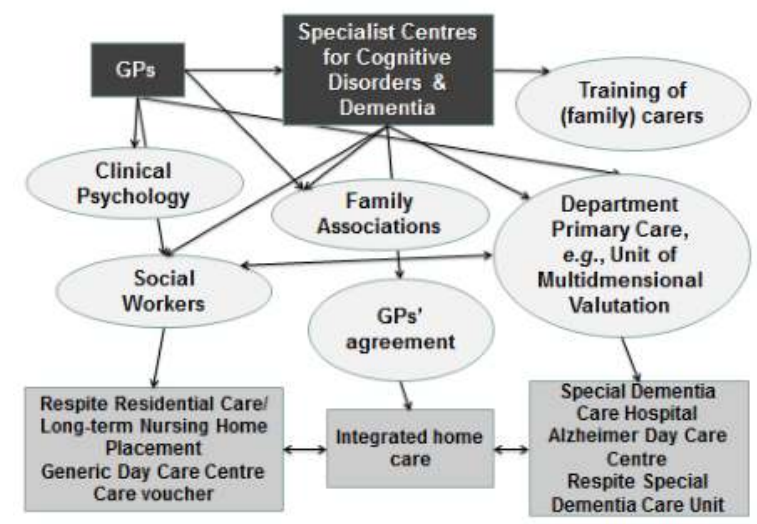

Figure 1. Network of health and social services for PWD 
In 2013, 2210 PWD have been followed in domiciliary care, representing $42 \%$ of the total number of PWD (5,195 forms B still active) cared for in the long term by the GPs. This percentage highlights how the use of in-home care is becoming an increasingly necessary care model for PWD, especially in the end-stage of the disease. Indeed, an analysis of the nursing care activities documents a prevalence of interventions for complications typical of late-stage dementia, such as the treatment of pressure ulcers (representing $44 \%$ of total domiciliary nurse activities). Overall these data indicate that dementia has become the second most important disease (after chronic heart failure, but before cancer disease) in contrast to what happened before where cancer care at home exceeded that for dementia.

\subsection{The Modena project: from the present to the future}

The next step of the Modena project is the introduction of an indicator of the quality of care of PWD in primary care as suggested also by the recent National Dementia Plan (October 2014). The intention is to substitute the hard-copy reports (Form B) with manual extraction of data with an electronic format provided by a software house containing, besides information about demographic and clinical data, additional biochemical and instrumental tests and pharmaceutical treatment (Table 4).

\begin{tabular}{|c|c|c|c|c|c|}
\hline & & 0 points & 5 points & 10 points & Source \\
\hline 1 & $\begin{array}{l}\text { Presence of PEG/feeding } \\
\text { tube }\end{array}$ & YES & -- & $\mathrm{NO}$ & $\begin{array}{l}\mathrm{ADI} \text { web/CCI/ABC } \\
\text { software for } \mathrm{NH}\end{array}$ \\
\hline 2 & Use of antipsychotics & $\begin{array}{l}\text { YES }>90 \text { days of } \\
\text { therapy/year }\end{array}$ & $\begin{array}{l}\text { YES but }>90 \text { days } \\
\text { of therapy/year }\end{array}$ & $\mathrm{NO}$ & $\begin{array}{l}\mathrm{ADI} \text { web/CCI/ABC } \\
\text { software for } \mathrm{NH}\end{array}$ \\
\hline 3 & $\begin{array}{l}\text { HbA1c in diabetes } \\
\text { mellitus }\end{array}$ & $\begin{array}{l}\mathrm{HbA} 1 \mathrm{c}<6,5 \% \text { o }> \\
8,5 \%\end{array}$ & $6,5 \%<\mathrm{HbA} 1 \mathrm{c}<7,5 \%$ & $\begin{array}{l}7,5 \%<\mathrm{HbA} 1 \mathrm{c}< \\
\% 8,5 \% \text { or No } \\
\text { Diabetes mellitus }\end{array}$ & $\mathrm{CCI}$ \\
\hline 4 & $\begin{array}{l}\text { Use of benzodiazepines o } \\
\text { hypnotics }\end{array}$ & $\begin{array}{l}\text { rYes }>30 \text { days of } \\
\text { therapy/year }\end{array}$ & $\begin{array}{l}\text { Yes but } \leq 30 \text { days of } \\
\text { therapy/year }\end{array}$ & No & $\mathrm{CCI}$ \\
\hline 5 & Use of fluoroquinolones & YES & $\begin{array}{l}\text { YES but } \leq 2 \text { blisters, } \\
\text { year }\end{array}$ & No & $\mathrm{CCI}$ \\
\hline 6 & $\begin{array}{l}1 \text { ECG/year in patients } \\
\text { who uses antipsychotics }\end{array}$ & No & -- & $\begin{array}{l}\text { Yes or No } \\
\text { antipsychotic } \\
\text { therapy }\end{array}$ & $\mathrm{CCI}$ \\
\hline 7 & 1 creatinemia /year & No & -- & Yes & $\mathrm{CCI}$ \\
\hline 8 & $\begin{array}{l}\text { Blood Pressure (BP) } \\
\text { Measurement }\end{array}$ & No & $\begin{array}{l}\mathrm{BP}<110 / 70 \mathrm{mmHg} \\
\mathrm{BP}>140 / 90 \mathrm{mmHg}\end{array}$ & $\begin{array}{l}110 / 70 \mathrm{mmHg}<\mathrm{BP}< \\
140 / 90 \mathrm{mmHg}\end{array}$ & $\mathrm{CCI}$ \\
\hline 9 & $1 \mathrm{NPI} /$ year & No & -- & Yes & $\mathrm{CCI} / \mathrm{CCDD}$ \\
\hline 10 & 1 PAINAD/year & No & -- & Yes & $\mathrm{CCI} / \mathrm{CCDD}$ \\
\hline
\end{tabular}

CCI, medical records data; CCDD, centre for cognitive disorders and dementia; ADI, health in-home care; $\mathrm{NH}$ nursing home; NPI, neuropsychiatric inventory and PAINAD, pain in advanced dementia.

Table 4. The QUADISC composite indicator 
The collected data will be integrated and assembled into a single database and analysed in collaboration with the Department of Clinical Epidemiology of the ASL of Modena, in order to develop a reporting, including the introduction of a composite indicator of quality of care, following the recommendations of the "Choosing Wisely" of the American Geriatrics Society $[114,115]$ and from other evidence-based medicine data in elderly PWD [116-123].

This composite indicator, called QuADisC (Qualità dell'Assistenza al paziente con Disturbi Cognitivi, Quality of care of the patient with cognitive disorders), consists of 10 items (Table 4). For each item a score of 0,5 or 10 is assigned, respectively, for non-target (or missing data), partially or fully achieved action on the part of the GP. The sum produces an overall score (maximum 100) that is directly proportional to the effectiveness of the care of the PWD.

For each patient, the total score will be calculated automatically within a clinical database that integrates demographic information and other clinical data provided by the GPs. There will be a refunding for the GP who sends the required data.

The QuADisC will be validated by correlating with an indicator of the effectiveness of care based on the number of (a) ER visits, (b) hospital admissions; (c) nursing home placement and (d) mortality, specifying reasons of ER referrals, admission to acute hospital wards or a nursing home and possibly the cause of the exitus.

\section{Conclusions}

Primary care is pivotal to the delivery of good quality assessment and care for PWD. There is a need for greater dementia-specific awareness through education and the organisation of systems both within practices and across interfaces between organisations. There are at least three specific areas that need addressing to improve care of PWD in primary care (1) necessity to standardise assessment tools and to use innovative technologies to facilitate early diagnosis; (2) opportunity to increase awareness of the benefits of psychosocial interventions in primary care for PWD, such as psychological interventions for CGs, cognitive stimulation and occupational therapy and (3) possibility to promote knowledge on the use of drugs by PWD and an enhancement of supportive strategies for patients and carers.

It is hoped that the introduction of a "collaborative model," such as the 'Modena network' (Figure 1), with measurable indicators of appropriateness of care by the GP (see QuADisC, Table 4) will further improve the quality of care for PWD and their CGs in the context of primary care.

\section{Author details}

Luc Pieter De Vreese*, Luigi De Salvatore, Lara Rovesta and Andrea Fabbo*

*Address all correspondence to: 1.devreese@ausl.mo.it; a.fabbo@ausl.mo.it

Dementia Programme, Health Trust, Local Authority for Health of Modena (ASL), Modena, Italy 


\section{References}

[1] Alzheimer's Disease International. The Global Impact of Dementia. An analysis of prevalence, incidence, cost and trends. London: Alzheimer's Disease International (ADI), 2015.

[2] Lucca U, Tettamanti M, Tiraboschi P, et al. Prevalence of dementia in the oldest old: the Monzino 80-plus population based study. Alzheimers Dement 2015;11:258-70.

[3] American Psychiatric Association. Diagnostic and statistical manual of mental disorders. (5th ed.). Washington, DC: American Psychiatric Association, 2013.

[4] Steinberg M, Shao H, Zandi P, et al. Point and 5-year period prevalence of neuropsychiatric symptoms in dementia: the Cache County Study. Int J Geriatr Psychiatry 2008;23:170-7.

[5] Nelson T, Livingston G, Knapp M, Manela M, Kitchen G, Katona C. Slicing the health service cake: the Islington study. Age Ageing 2002;31:445-50.

[6] Moriarty JM. Use of community and long-term care by people with dementia in the UK: a review of some issues in service provision and carer and user preferences. $\mathrm{Ag}$ ing Ment Health 1999;3:311-9.

[7] Brodaty H, Thomson C, Thompson C, Fine M. Why caregivers of people with dementia and memory loss don't use services. Int J Geriatr Psychiatry 2005;20:537-46.

[8] Reilly S, Miranda-Castillo C, Sandhu S, Hoe J, Challis D, Orrell M. Case management approaches to home support for people with dementia. Cochrane Database Syst Rev 2015;1:CD008345.

[9] Koch T, Iliffe S. Rapid appraisal of barriers to the diagnosis and management of patients with dementia in primary care: a systematic review. BMC Fam Pract 2010;11:52.

[10] Van Hout H, Vernooij-Dassen M, Bakker K, Blom M, Grol R. General practitioners on dementia: tasks, practices and obstacles. Patient Educ Couns 2000;39:219-25.

[11] Bradford A, Kunik ME, Schulz P, Williams SP, Singh H. Missed and delayed diagnosis of dementia in primary care: prevalence and contributing factors. Alzheimer Dis Assoc Disord 2009;23:306-14.

[12] Hinton L, Franz CE, Reddy G, Flores Y, Kravitz RL, Barker JC. Practice constraints, behavioral problems, and dementia care: primary care physicians' perspectives. J Gen Intern Med 2007;22:1487-92.

[13] Pimlott NJG, Persaud M, Drummond N, et al. Family physicians and dementia in Canada. Part 2. Understanding the challenges of dementia care. Can Fam Physician 2009;55:508-9.e1-7. 
[14] Ganguli M, Rodriguez E, Mulsant B, et al. Detection and management of cognitive impairment in primary care: the Steel Valley seniors survey. I Am Geriatr Soc 2004;52:1668-75.

[15] Turner S, Iliffe S, Downs M, Wilcock J, et al. General practitioners' knowledge, confidence and attitudes in the diagnosis and management of dementia. Age Ageing 2004;33:461-7.

[16] Iliffe S, Wilcock J. The identification of barriers to the recognition of, and response to, dementia in primary care using a modified focus group approach. Dementia 2005;4:73-85.

[17] Foster NL. Barriers to treatment: the unique challenges for physicians providing dementia care. J Geriatr Psychiatry Neurol 2001;14:188-98.

[18] Valcour VG, Masaki KH, Curb D, Blanchette PL. The detection of dementia in the primary care setting. Arch Intern Med 2000;160:2964-8.

[19] Hutchings D, Vanoli A, McKeith I, Brotherton S, Mcnamee P, Bond J. Cholinesterase inhibitors and Alzheimer's disease: patient, care and professional factors influencing the use of drugs for Alzheimer's disease in the United Kingdom. Dementia 2010;9:427-43.

[20] Pimlott NJG, Siegel K, Persaud M, et al. Management of dementia by family physicians in academic settings. Can Fam Physician 2006;52:1108-9.

[21] Franz CE, Barker JC, Kim K, et al. When help becomes a hindrance: mental health referral systems as barriers to care for primary care physicians treating patients with Alzheimer's disease. Am J Geriatr Psychiatry 2010;18:576-85.

[22] Cantegreil-Kallen I, Turbelin C, Angel P, Flahault A, Rigaud A. Dementia management in France: health care and support services in the community. Dementia 2006;5:317-26.

[23] Phelan EA, Borson S, Grothaus L, Balch S, Larson EB. Association of incident dementia with hospitalizations. J Am Med Assoc 2012;307:165-72.

[24] Burns R, Nichols LO, Martindale-Adams J, Graney MJ, Lummus A. Primary care interventions for dementia caregivers: 2-year outcomes from the REACH study. Gerontologist 2003;43:547-55.

[25] Vickrey BG, Mittman BS, Connor KI, et al. The effect of a disease management intervention on quality and outcomes of dementia care: a randomized, controlled trial. Ann Intern Med 2006;145:713-26.

[26] Downs M, Turner S, Bryans M, et al. Effectiveness of educational interventions in improving detection and management of dementia in primary care: cluster randomized controlled study. Br Med J 2006;332:692-6. 
[27] Chodosh J, Berry E, Lee M, et al. Effect of a dementia care management intervention on primary care provider knowledge, attitudes, and perceptions of quality of care. J Am Geriatr Soc 2006;54:311-7.

[28] Waldorff FB, Almind G, Makela M, Moller S, Waldemar G. Implementation of a clinical dementia guideline: a controlled study on the effect of a multifaceted strategy. Scand J Prim Health Care 2003;21:142-7.

[29] Callahan CM, Boustani MA, Unverzagt FW, et al. Effectiveness of collaborative care for older adults with Alzheimer disease in primary care: a randomized controlled trial. J Am Med Assoc 2006;295:2148-57.

[30] Johansson G, Eklund K, Gosman-Hedstrom G. Multidisciplinary team, working with elderly persons living in the community: a systematic literature review. Scand J Occup Ther 2010;17:101-16.

[31] Parmar J, Dobbs CB, McKay R, et al. Diagnosis and management of dementia in primary care. Can Fam Physician 2014;60:457-65.

[32] Donaldson MS. Continuity of care: a reconceptualization. Med Care Res Rev 2001;58:255-90.

[33] Cockerill R, Jaglal S, Charles LL, Chambers L, Brazil K, Cohen C. Components of coordinated care: a new instrument to assess caregivers' and care recipients' experiences with networks of dementia care. Dementia 2006;5:51-66.

[34] Prince M, Bryce R, Ferri C. World Alzheimer Report 2011: the benefits of early diagnosis and intervention. Alzheimer's Disease International: London, 2011. Available at: www.alz.co.uk/research/world-report. Accessed on April 3, 2014.

[35] Phillips J, Pond D, Goode SM. Timely Diagnosis of Dementia: Can we do better? A report for Alzheimer's Australia, 2011. Available at: www.alzheimers.org.au. Accessed on April 3, 2014.

[36] Bamford C, Eccles M, Steen N, Robinson L. Can primary care record review facilitate earlier diagnosis of dementia? Fam Pract 2007; 24:108-16.

[37] Pond CD, Brodaty H, Stocks NP, et al. Ageing in general practice (AGP) trial: a cluster randomised trial to examine the effectiveness of peer education on GP diagnostic assessment and management of dementia. BMC Fam Pract 2012;13:12.

[38] Justiss MD, Boustani M, Fox C et al. Patients' attitudes of dementia screening across the Atlantic. Int J Geriatr Psychiatry 2009; 24:632-7.

[39] Sullivan K, O'Conner F. Should a diagnosis of dementia be disclosed? Aging Ment Health 2001;5:340-8.

[40] Banerjee S,Owen J. Living Well with Dementia: A National Dementia Strategy. Department of Health: London, 2009. 
[41] Edwards R, Voss S and Illife S. Education about dementia in primary care: Is personcentredness the key? Dementia 2014;13:111-9.

[42] Downs M, Turner S, Bryans M, et al. Effectiveness of educational interventions in improving detection and management of dementia in primary care: cluster randomised controlled study. Br Med J 2006; 332:692-6.

[43] Illife $S$ and Koch T. Tailored education rather than financial incentives are effective educational interventions for primary dementia care. Int J Geriatr Psychiatry 2012;27:764-5.

[44] Kennedy A, Reeves D, Bower P, et al. Implementation of self-management support for long-term conditions in routine primary care settings: a cluster randomized controlled trial. Br Med J 2013;346:2882.

[45] Schoenmakers B, Buntinx F, Delepeleire J. What is the role of the general practitioner towards the family caregiver of a community-dwelling demented relative? A systematic literature review. Scand J Prim Health Care 2009;27:31-40.

[46] Wilkins CH, Wilkins KL, Meisel M, Depke M, Williams J, Edwards DF. Dementia undiagnosed in poor older adults with functional impairment. J Am Geriatr Soc 2007;55:1771-6.

[47] Eccles M, Clarke J, Livingstone M, et al. North of England evidence based guidelines development project: guide-line for the primary care management of dementia. $\mathrm{Br}$ Med J 1998;317:802-8.

[48] Agency for Healthcare Research and Quality. Recommendations of the U.S. Preventive Services Task Force: Guide to Clinical Preventive Services. AHRQ: Rockville, MD, 2005. Available at: www.ahrq.gov/clinic/pocketgd.pdf/. Accessed on December 22, 2013.

[49] National Collaborating Centre for Mental Health Dementia: the NICE/SCIE Guideline on Supporting People with Dementia and Their Carers in Health and Social Care. National Clinical Practice Guideline 42 and British Psychological Society and Royal College of Psychiatrists: Leicester and London, 2007.

[50] Folstein MF, Bassett SS, Romanoski AJ, Nestadt G. The epidemiology of delirium in the community: The eastern Baltimore mental health. Int Psychogeriatr 1991;3:169-76.

[51] Brodaty H, Pond D, Kemp NM, et al. The GPCOG: a new screening test for dementia designed for general practice. J Am Geriatr Soc 2002;50:530-4.

[52] Borson S, Scanlan J, Brush M et al. The mini-cog: a cognitive 'vital signs' measure for dementia screening in multi-lingual elderly.. Int J Geriatr Psychiatry 2000;15:1021-7.

[53] Buschke H, Kuslansky G, Katz M, et al. Screening for dementia with the Memory Impairment Screen. Neurology 1999;52:231-8.

[54] Brooke P, Bullock R. Validation of a 6-item cognitive impairment test with a view to primary care usage. Int J Geriatr Psychiatry 1999;14:936-40. 
[55] Shulman KI. Clock-drawing: is it the ideal cognitive screening test? Int J Geriatr Psychiatry 2000;15:548-61.

[56] New Recommendations for Detection of Cognitive Impairment During Medicare Annual Wellness Visit. Available at: http://www.alz.org/professionals_and_researchers_14294.asp\#assessvideos. Accessed on May 7, 2013.

[57] Galvin JE, Roe CM, Powlishta KK, et al. The AD8: a brief informant interview to detect dementia. Neurology. 2005;65:559-64.

[58] Mitchell AJ, Malladi S. Screening and case finding tools for the detection of dementia. Part I: evidence-based meta-analysis of multidomain tests. Am J Geriatr Psychiatry 2010;18:759-82.

[59] Cordell CB, Borson S, Boustani M, et al. Medicare Detection of Cognitive Impairment Workgroup. Alzheimer's Association recommendations for operationalizing the detection of cognitive impairment during the Medicare annual wellness visit in a primary care setting. Alzheimers Dement. 2013;9:141-50.

[60] Geldmacher DS, Kerwin DR. Practical Diagnosis and Management of Dementia Due to Alzheimer's Disease in the Primary Care Setting: An Evidence-Based Approach. Prim Care Companion CNS Disord 2013;15(4). Published online 2013 Aug 23. Doi: 10.4088:PCC12r Published

[61] Young J, Anstey KJ, Cherbuin N. Online memory screening - are older adults interested and can it work? Aging Ment Health 2012;16:931-7.

[62] Dementia Collaborative Research Centre - Assessment and Better Care, University of New South Wales, Sydney, NSW, Australia - The Royal Australian College of General Practitioners (2011). "14 Essentials for Good Dementia Care in General Practice". Available at: http://www.dementiaresearch.org.au/. Accessed on April 3, 2014.

[63] Villars H, Oustric S, Andrieu S, et al. The primary care physician and Alzheimer's disease: an international position paper. J Nutr Health Aging 2010;14:100-20.

[64] Waldemar G, Dubois B, Emre M, et al. Recommendations for the diagnosis and management of Alzheimer's Disease and other disorders associated with dementia: EFNS guideline. Eur J Neurol 2007;14: e1-e26.

[65] Alzheimer's Society. Diagnosis and Assessment. Factsheet 426LP Last reviewed: August 2014. Registered charity no. 296645. A company limited by guarantee and registered in England no. 2115499. Available at: http://www.alzheimers.org.uk/. Accessed on April 3, 2015.

[66] Alzheimer's Association. 2011 Alzheimer's disease facts and figures. Alzheimers Dement 2011;7:208-44.

[67] Balasa M, Gelpi E, Antonell A, et al. Clinical features and APOE genotype of pathologically proven early-onset Alzheimer disease. Neurology 2011;76:1720-5. 
[68] Pirani A, Brodaty H, Martini E, Zaccherini D, Neviani F, Neri M. The validation of the Italian version of the GPCOG (GPCOG-It): a contribution to cross-national implementation of a screening test for dementia in general practice. Int Psychogeriatr 2010;22:82-90.

[69] Pirani, Brodaty H, Zaccherini D, Tulipani C, Neri M. A Proposal to Improve Early Diagnosis of Dementia in General Practice. National Dementia Research Forum: Sydney, Australia, 22-23 September 2011.

[70] Apostolova LG, Cummings JL. Neuropsychiatric manifestations in mild cognitive impairment: a systematic review of the literature. Dement Geriatr Cogn Disord 2008;25:115-26.

[71] Boustani MA, Sachs GA, Alder CA, et al. Implementing innovative models of dementia care: the healthy aging brain center. Aging Ment Health 2011;15:13-22.

[72] Callahan CM, Boustani MA, Weiner M, et al. Implementing dementia care models in primary care settings: The Aging Brain Care Medical Home. Aging Ment Health 2011;15:5-12.

[73] Low L-F, Fletcher J. Models of home care services for people with dementia: a narrative review. Int Psychogeriatr 2015;12:1-8.

[74] Moniz-Cook E, Vernooij Dassen M, Woods B, et al. Psychosocial interventions in dementia care research: the INTERDEM manifesto. Aging Ment Health 2011;15:283-90.

[75] Smits CH, de Lange J, Dröes RM, Meiland F, Vernooij-Dassen, Pot Am. Effects of combined intervention programmes for people with dementia living at home and their caregivers: a systematic review. Int J Geriatr Psychiatry 2007;22:1181-23.

[76] Olazarán J, Reisberg B, Clare L, et al. Nonpharmacological therapies in Alzheimer's disease: a systematic review of efficacy. Dement Geriatr Cogn Disord 2010;30:161-78.

[77] Robinson L, Iliffe S, Brayne C, et al. Primary care in dementia: 2 long-term care at home: psychosocial interventions, information provision, carer support and case management. Int J Geriatr Psychiatry 2010;25:657-64.

[78] Vernooij-Dassen M, Draskovic I, McCleery J, et al. Cognitive reframing for carers of people with dementia. Cochrane Database Syst Rev 2011; Nov 9;(11):CD005318.

[79] Spector A, Thorgrimsen L, Woods B, et al. Making a Difference: An Evidence-Based Group Programme to Offer Cognitive Stimulation Therapy (CST) to People with Dementia. Hawker Publications: London, 2006.

[80] Woods B, Aguirre E, Spector AE et al. Cognitive stimulation to improve cognitive functioning in people with dementia. Cochrane Database Syst Rev 2012; 2:CD005562.

[81] Spector A, Thorgrimsen L, Woods RT, et al. Efficacy of an evidence-based cognitive stimulation therapy programme for people with dementia: randomised controlled trial. Br J Psychiatry 2003; 183:248-54. 
[82] Bunn F, Goodman C, Sworn K, et al. Psychosocial factors that shape patient and carer experiences of dementia diagnosis and treatment: a systematic review of qualitative studies. PLOS Medicine 2012; 9:e1001331.

[83] Clare L, Linden DEJ, Woods RT, et al. Goal-oriented cognitive rehabilitation for people with early-stage Alzheimer disease: a single-blind randomized controlled trial of clinical efficacy. Am J Geriatr Psychiatry 2010;18:928-39.

[84] Graff MJ, Vernooij-Dassen MJ, Thijssen M, et al. Effects of community occupational therapy on quality of life, mood, and health status in dementia patients and their caregivers: a randomized controlled trial. J Gerontol A: Biol Sci Med Sci 2007;62:10029 .

[85] Perry M, Draskovic I, Lucassen P, et al. Effects of educational interventions on primary dementia care: a systematic review. Int J Geriatr Psychiatry 2011;26:1-11.

[86] Connoly A, Iliffe S, Gaehl S, et al. Quality of care provided to people with dementia: utilisation and quality of the annual review in general practice. Br J Gen Pract 2012;62:e91-8.

[87] Vasse E, Moniz-Cook E, Olde Rikkert M, et al. The development of quality indicators to improve psychosocial care in dementia. Int Psychogeriatr 2012;24:921-30.

[88] Iliffe S, Wilcock J, Haworth D. Delivering psychosocial interventions for people with dementia in primary care: jobs or skills? Dementia: Int J Soc Res Pract 2006;5:327-38.

[89] Hodge S, Doncaster E, Moniz-Cook E, et al. Two sides of the same coin? Patients' and carers' views of UK memory services. Aging Health 2013;9:275-80.

[90] World Health Organisation (2008). Integrated Health Services - What and Why. Technical Brief No. 1, 2008. Available at http://www.who.int/healthsystems/service_delivery_techbrief1.pdf. Accessed on April 9, 2015.

[91] Maidment ID, Fox C, Boustani M, Katona C. Medication management - the missing link in dementia interventions. Int J Geriatr Psychiatry 2012;27:439-42.

[92] Department of Health. The Use of Antipsychotic Medication for People with Dementia: Time for Action. Stationary Office: London. Available at: www.dh.gov.uk/en/Publicationsandstatistics/Publications/PublicationsPolicyAndGuidance/DH_108303/. Accessed May 7, 2013.

[93] Smith F, Francis SA, Gray N, Denham M, Graffy J. A multi-centre survey among informal carers who manage medication for older care recipients: problems experienced and development of services. Health Soc Care Community 2003;11:138-45.

[94] Maidment ID, Haw C, Stubbs J, et al. Medication errors in older people with mental health problems: a review. Int J Geriatr Psychiatry 2008;23:564-73.

[95] Maidment ID, Parmentier H. Medication error in mental health: implications for primary care. Ment Health Fam Med 2009;6:203-7. 
[96] National Institute of Clinical Excellence. Falls: assessment and prevention of falls in older people. NICE: London, 2013. Available at: http://www.guidance.nice.org.uk/CG161/. Accessed on May 7, 2013.

[97] Gill SS, Anderson GM, Fischer HD, et al. Syncope and its consequences in patients with dementia receiving cholinesterase inhibitors: a population-based cohort study. Arch Intern Med 2009;169:867-73.

[98] Pimouguet C, Lavaud T, Dartigues J, Helmer C. Dementia case management effectiveness on health care costs and resource utilization: a systematic review of randomized controlled trials. J Nutr Health Aging 2010;14(8):669-76.

[99] Mittelman M, Haley W, Clay O, Roth D. Improving caregiver well-being delays nursing home placement of patients with Alzheimer Disease. Neurology 2006;67:1592-9.

[100] Chien WT, Lee YM. A disease management program for families of persons in Hong Kong with dementia. Psychiatr Serv 2008;59:433-6.

[101] Vickery B, Mittman B, Connor K, et al. The effect of disease management intervention study on quality and outcomes of dementia care. Ann Intern Med 2006;145:71372.

[102] Tam-Tham H, Cepoiu-Martin M, Ronksley P E, Maxwell C J, Hemmelgarn BR. Dementia case management and risk of long-term care placement: a systematic review and meta-analysis. Int J Geriatr Psychiatry 2013;28:889-902.

[103] Somme D, Trouve H, Dramé M, Gagnon D, Couturier Y, Saint-Jean, O. Analysis of case management programs for patients with dementia: a systematic review. Alzheimers Dementia 2012;8:426-36.

[104] Eloniemi-Sulkava U, Notkola IL, Hentinen M, Kivela SL, Sivenius J, Sulkava R. Effects of supporting community-living demented patients and their caregivers: a randomized trial. J Am Geriatr Soc 2001;49:1282-7.

[105] Khanassov V, Vedel I, Pluye P. Case management for dementia in primary health care: a systematic mixed studies review based on the diffusion of innovation model. J Clin Intervent Aging 2014;9:915-28.

[106] Béland F, Bergman H, Lebel P, et al. Integrated services for frail elders (SIPA): a trial of a model for Canada. Can J Aging 2006;25:5-42.

[107] Chatterji P, Burstein NR, Kidder D, White A. Evaluation of the Program of All-Inclusive Care for the elderly (PACE) Demonstration: The Impact of PACE on Participants Outcomes. Abt Associations: Cambridge, MA. 1998.

[108] Fabbo A, Capelli O, De Luca ML, De Vreese LP, et al. A model of integrated care for people with dementia in primary care. Int J Integr Care. 2014 (WCIC Conf Suppl) URN:NBN:NL:UI:10-1-116641. 
[109] Mundt JC, Ferber KL, Greist JH. Symptoms of dementia screener (SDS): treatment and community screening. Gerontologist. 2001;41: 131-2.

[110] Patricia PA, et al. Validation of the Cumulative Illness Rating Scale in a geriatric residential population. J Am Geriatr Soc 1995; 43.2:130-7.

[111] Graf, C. The Lawton instrumental activities of daily living scale. Am J Nurs 2008;108(4):52-62.

[112] Katz S, et al. Studies of illness in the aged: the index of ADL: a standardized measure of biological and psychosocial function. JAMA 1963;185:914-9.

[113] First MB. Structured Clinical Interview for DSM-IV-TR Axis I Disorders: Patient Edition. Biometrics Research Department, Columbia University, 2005.

[114] Mulhausen P, Chun A, Green A,et al. American Geriatrics Society identifies five things that healthcare providers and patients should question. I Am Geriatr Soc 2013;6:622-31.

[115] Chun A, Green A, Hayward A, et al. American Geriatrics Society identifies another five things that healthcare providers and patients should question. J Am Geriatr Soc 2014;62:950-60.

[116] Johnston B. Delirium in the Elderly. Primary Care Geriatric Lectures, University of California. Available at https://www.coursehero.com/file/6643602/sfdelirium/. Accessed on April 9, 2015.

[117] Inouye S. A multicomponent intervention to prevent delirium in hospitalized older patients. Ann Intern Med 1993;119-474.

[118] Ungar A, Salti F, Di Bari M, Di Iorio A. Linee Guida sull'ipertensione arteriosa nell'anziano [Guidelines for hypertension in the elderly]. G Gerontol 2000;48:197-203.

[119] Gillespie D, Robertson M, Gillespie J, et al. Interventions for preventing falls in older people living in the community. Editorial Group: Cochrane Bone, Joint and Muscle Trauma Group. Published Online: September 12, 2012. Available at http://onlinelibrary.wiley.com/doi/10.1002/14651858.CD007146.pub3/. Accessed on April 3, 2015.

[120] Musini VM, Tejani AM, Bassett K, Wright JM. Pharmacotherapy for hypertension in the elderly. Cochrane Database Syst Rev. 2009;7(4):CD000028.

[121] Cummings JL, Mega M., Gray K, et al. The Neuropychiatric Inventory: a comprehensive assessment of psychopatology in dementia. Neurology, 1994;44:2308-14.

[122] Warden V, Hurley AC, Volicer L. Development and psychometric evaluation of the pain assessment in advanced dementia (PAINAD) scale. J Am Med Dir Assoc 2003;4:9-15.

[123] Sentagen EA, King SA. The problems of pain and its detection among geriatric nursing home residents. J Am Geriatr Soc 1993;41:541-4. 